\title{
RANCANG BANGUN MADING BERSUARA MENGGUNAKAN SENSOR GERAK (PIR) DI SD MUHAMMADIYAH 1 TEJOASRI - KAB. LAMONGAN
}

\author{
Wais Alqorni ${ }^{1}$, Triuli Novianti ${ }^{2}$ \\ Program studi d3 teknik komputer \\ Fakultas teknik \\ Universitas muhammadiyah surabaya \\ Surabaya, indonesia \\ triuli81@yahoo.com
}

\begin{abstract}
Abstrak
Audio sudah menjadi salah satu elemen yang penting bagi berbagai peran dalam membangun sebuah sistem komunikasi. Audio memiliki fungsi sebagai sarana yang mampu menyampaikan pesan sekaligus mempermudah penerimaan pesan dalam pemahamannya. Adanya sensor PIR yang terletak di bawah mading berfungsi sebagai alat pendeteksi gerakan manusia yang memberikan pancaran sinar infra merah. Sensor PIR bersifat pasif, artinya sensor ini tidak memancarkan sinar infra merah tetapi hanya menerima radiasi sinar infra merah dari luar sehingga jika ada pergerakan maka akan terjadi perubahan pembacaan pada sensor. Pada umumnya mading di sekolahan hanya berisi informasi berupa tulisan atau gambar saja maka penulis mencoba menambahkan informasi melalui audio. Yang dimaksud disini adalah menambahkan informasi audio lewat mp3 player. Audio akan bekerja ketika sensor gerak PIR ini mendeteksi seseorang yang melewatinya dari jarak kurang lebih $300 \mathrm{~cm}$. Alat ini bertujuan Sebagai sarana efektif untuk menyampaikan informasi tentang kegiatan dalam maupun luar sekolah sehingga siswa dan siswi akan mengetahui informasi-informasi yang terupdate. Dengan adanya mading bersuara ini informasi yang disajikan kepada siswa- siswi lebih variatif, tidak hanya gambar atau tulisan saja melainkan juga informasi lewat audio, serta juga dapat melatih kemampuan siswa dalam menyimak informasi melalui audio yang ada pada mading bersuara.
\end{abstract}

Kata Kunci : audio, mading, sensor gerak PIR

\begin{abstract}
Audio has become one of the elements that are important for a variety of roles in building a communications system. Audio has a function as a tool that is able to convey the message as well as facilitate the receipt of messages of understanding. The presence of PIR sensor located below the wall magazine serves as human motion detectors that provide infrared rays. PIR sensors are passive, meaning that the sensor does not emit infrared rays but only receives infrared radiation from the outside so that if there is movement there will be a change in the sensor readings. In general, mading in school only contains information in the form of text or image only, the author tries to add information via audio. What is meant here is adding audio information via the mp3 player. Audio will work when this PIR motion sensor detects a person who passes from a distance of approximately $300 \mathrm{~cm}$. The aim of this tool as an effective means to convey information about activities in and outside schools so that boys and girls will know the information is updated. With the voice Mading this information is presented to the learner and students more varied, not only the images or text only but also information via audio, and can also train the students' skills in listening to the information through the existing audio in a voice bulletin board.
\end{abstract}

Keywords: audio, Mading, PIR motion sensor 


\section{PENDAHULUAN}

Seiring dengan perkembangan zaman, sumber informasi atau berita kini semakin mudah kita dapatkan salah satunya adalah melalui media audio. Media audio menjadi salah satu elemen yang penting, karena ikut berperan dalam membangun sebuah sistem komunikasi dalam bentuk suara. Selain itu, media audio berfungsi sebagai sarana yang mampu menyampaikan pesan sekaligus mempermudah penerima pesan dalam memahami isi pesan. Pentingnya media komunikasi audio lainnya adalah mampu melatih segala kegiatan pengembangan keterampilan terutama yang berhubungan dengan aspek aspek keterampilan pendengaran.

Pemanfaatan Audio dapat dijadikan sebagai tambahan media informasi dalam bentuk suara yang ada di mading karna penyajian berita pada mading di sekolah umumnya bersifat visual, seperti tulisan, gambar atau kombinasi dari keduanya. Dengan demikian akan sangat membantu para siswa untuk meningkatkan kemampuan menyimak berita dengan baik,dan juga para siswa mendapat informasi tanpa harus membaca. Audio akan bekerja ketika Sensor PIR (Passive Infra Red) yang terpasang di bagian bawah mading mendeteksi adanya adalah sensor yang digunakan untuk mendeteksi adanya pancaran sinar infra merah.

\footnotetext{
Makalah ini membahas tentang rancang bangun mading bersuara menggunakan sensor gerak PIR di SD Muhammadiyah 1 Tejoasri Kab Lamongan yang meliputi : perancangan alat mading bersuara agar memberikan informasi kepada siswa siswi meskipun tidak membaca informasi madding secara langsung.
}

Adapun batasan permasalahan pada makalah ini antara lain : penggunaan tombol next untuk mendengarkan berita selanjutnya, perekaman suara di rekam melalui handphone atau lewat multi track recording dan berita yang di sampaikan hanya tag linenya saja.

Tujuan dari makalah ini antara lain : merancang dan membangun mading bersuara menggunakan sensor gerak PIR di SD Muhammadiyah 1 Tejoasri Kab Lamongan sebagai sarana efektif untuk menyampaikan

informasi sekolah melalui media audio dan sebagai sarana informasi yang efektif tentang kegiatan dalam maupun luar sekolah.

Metodelogi penelitian yang digunakan pada makalah ini adalah : pertama melakukan observasi yakni pengumpulan data dengan cara melakukan pengamatan dan pencatatan data serta berbagai hal yang di butuhkan dalam proses penelitian. Kedua, studi pustaka merupakan metode pencarian dan pengumpulan data dengan cara mencari refrensi, literatur atau bahan - bahan teori yang di perlukan dari berbagai sumber wacana melalui internet, buku- buku yang membahas mading, serta buku-buku tentang audio. Ketiga, desain dan perancangan mading yang akan dibuat. Keempat, pengujian alat yang telah dibuat. Kelima, analisa dan kesimpulan.

Sistematika makalah ini secara keseluruhan tercakup dalam lima bab sebagai berikut : bab pertama pendahuluan, kedua landasan teori, ketiga perancangan dan implementasi sistem, keempat pengujian sistem dan terakhir penutup, kesimpulan dan saran. 


\section{DASAR TEORI}

\section{Pengertian Majalah Dinding}

Majalah dinding atau yang biasa diakronimkan menjadi mading adalah salah satu jenis media komunikasi massa tulis yang paling sederhana. Disebut majalah dinding karena prinsip dasar majalah terasa dominan di dalamnya, sementara itu penyajiannya biasanya dipampang pada dinding atau yang sejenisnya.

Prinsip majalah tercermin lewat penyajiannya, baik yang berwujud tulisan, gambar, atau kombinasi dari keduanya.Dengan prinsip dasar bentuk kolom-kolom, bermacam-macam hasil karya, seperti lukisan, vinyet, teka-teki silang, karikatur, cerita bergambar, dan sejenisnya disusun secara variatif.Semua materi itu disusun secara harmonis sehingga keseluruhan perwajahan mading tampak menarik. Bentuk fisik mading biasanya berwujud lembaran tripleks, karton, atau bahan lain dengan ukuran yang beraneka ragam. Ukuran yang tergolong relatif besar adalah $120 \mathrm{~cm} \times 240 \mathrm{~cm}$, sedang yang lebih kecil lagi disesuaikan dengan situasi dan kondisinya.

\section{SENSOR GERAK (PIR HC-SR501)}

Sensor PIR (Passive Infra Red) adalah sensor yang digunakan untuk mendeteksi adanya pancaran sinar infra merah.Sensor PIR bersifat pasif, artinya sensor ini tidak memancarkan sinar infra merah tetapi hanya menerima radiasi sinar infra merah dari luar.

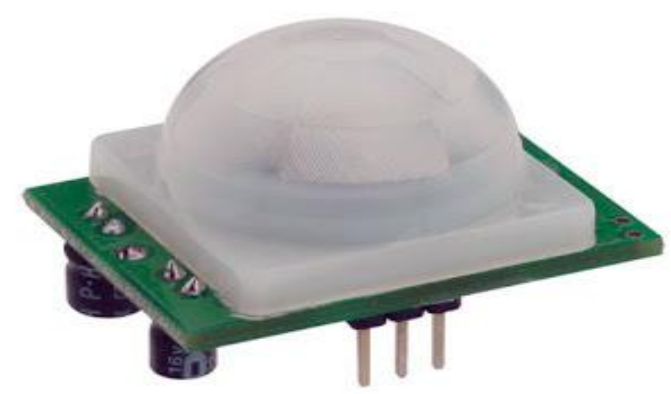

Gambar 1 Sensor PIR

Sensor ini biasanya digunakan dalam perancangan detektor gerakan berbasis PIR. Karena semua benda memancarkan energi radiasi, sebuah gerakan akan terdeteksi ketika sumber infra merah dengan suhu tertentu (misal: manusia) melewati sumber infra merah yang lain dengan suhu yang berbeda (misal: dinding), maka sensor akan membandingkan pancaran infra merah yang diterima setiap satuan waktu, sehingga jika ada pergerakan maka akan terjadi perubahan pembacaan pada sensor. Sensor PIR terdiri dari beberapa bagian yaitu : lensa fresnel, penyaring infra merah, sensor pyroelektrik, penguat amplifier dan komparator.

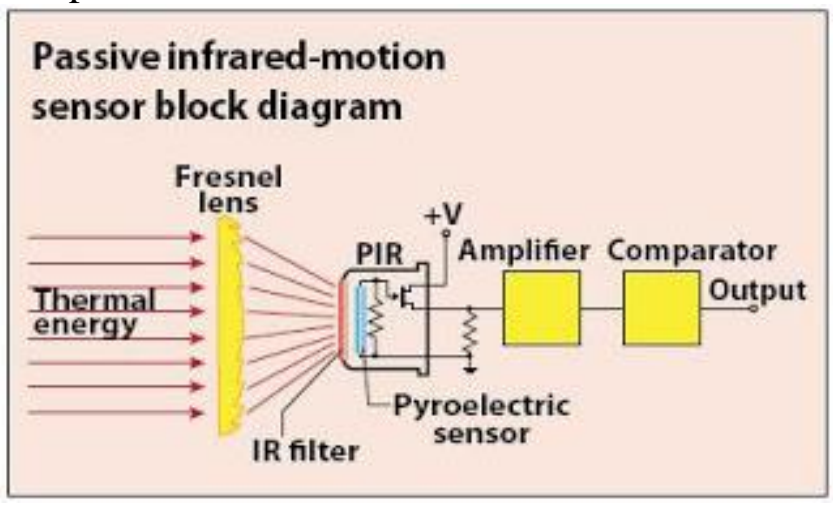

\section{Gambar 2 Passive Inrared-Motion Sensor Diagram}

- Cara kerja pembacaan sensor PIR Pancaran infra merah masuk melalui lensa Fresnel dan mengenai sensor pyroelektrik, karena sinar infra merah mengandung energi panas maka sensor pyroelektrik akan menghasilkan arus listrik. Sensor pyroelektrik terbuat dari bahan galium nitrida $(\mathrm{GaN})$, cesium nitrat (CsNo3) dan litium tantalate (LiTaO3). Arus listrik inilah yang akan menimbulkan tegangan dan dibaca secara analog oleh sensor. Kemudian sinyal ini akan dikuatkan oleh penguat dan dibandingkan oleh komparator dengan tegangan referensi tertentu (keluaran berupa sinyal 1-bit). Jadi sensor PIR hanya akan mengeluarkan logika 0 dan 1,0 saat sensor tidak mendeteksi adanya pancaran infra merah dan 1 saat sensor mendeteksi infra merah. Sensor PIR didesain dan dirancang hanya mendeteksi pancaran infra merah dengan 
panjang gelombang 8-14 mikrometer. Diluar panjang gelombang tersebut sensor tidak akan mendeteksinya. Untuk manusia sendiri memiliki suhu badan yang dapat menghasilkan pancaran infra merah dengan panjang gelombang antara 9-10 mikrometer (nilai standar 9,4 mikrometer), panjang gelombang tersebut dapat terdeteksi oleh sensor PIR. (Secara umum sensor PIR memang dirancang untuk mendeteksi manusia).

\section{METODE PENELITIAN}

Perancangan media yang diajukan adalah sebuah rancangan mading yang dapat memberikan informasi kepada siswa siswi SD Muhammadiyah 1 Tejoasri melalui audio yang di rekam di handphone atau komputer untuk convert menjadi format mp3 sehingga dapat di putar di mp3. Rancangan mading ini diberi sensor gerak PIR untuk menangkap adanya pergerakan manusia sehingga audio akan berkerja secara otomatis untuk mengeluarkan suara rekaman yang telah di simpan di mp3.

Perancangan mading berisi mengenai informasi sekolah seperti pengumuman pengumuman penting yang hendak disampaikan pada siswa. kegiatan-kegiatan lomba untuk siswa.kegiatan sekolah seperti informasi kegiatan ekstrakrikuler, dan lain sebagainya. Perancangan mading ini mempunyai kemampuan memberikan informasi hanya dengan melewati depan mading. Sasaran aplikasi ini di tujukan sebagai sarana informasi untuk siswa-siswa SD Muhammadiyah 1 Tejoasri Lamongan.

Analisis Perancangan alat pada peracangan mading bersuara dengan sensor PIR membutuhkan alat-alat sebagai berikut : Sensor gerak PIR, Memory card, Mp3, Push buton Button dan Mikrokontroler.

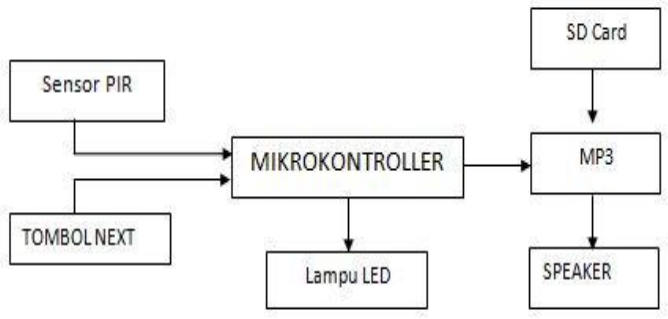

Gambar 3 Diagram Block Mading Bersuara

Sensor gerak PIR Berfungsi untuk menangkap gerakan manusia. Push Button untuk memindah informasi selanjutnya. Speaker untuk memperkeras suara. SD CARD untuk menyimpan informasi. Lampu Led sebagai tanda apabila sensor pir menangkap sinyal .

Berikut ini adalah flowchart dari perancangan sistem mading bersuara :

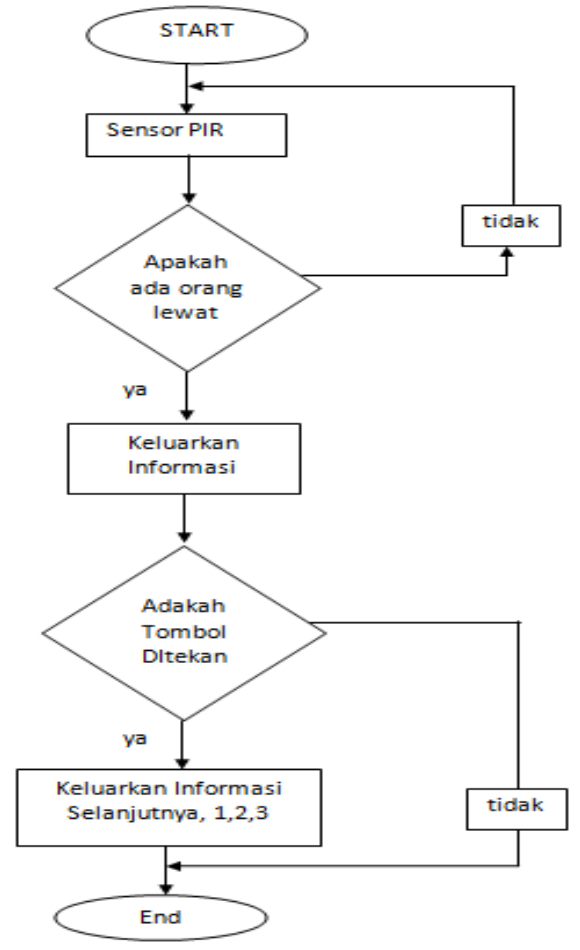

Gambar 4 Flowchart Program Mading bersuara dengan sensor PIR

Gambar di atas menjelaskan bahwa jika ada seseorang lewat di depan mading maka audio akan mengeluarkan berita pertama. Sensor PIR digunakan dalam perancangan detektor gerakan berbasis PIR. 
Karena semua benda memancarkan energi radiasi, sebuah gerakan akan terdeteksi ketika sumber infra merah dengan suhu tertentu (misal: manusia) melewati sumber infra merah yang lain dengan suhu yang berbeda (misal: dinding), maka sensor akan membandingkan pancaran infra merah yang diterima setiap satuan waktu, sehingga jika ada pergerakan maka akan terjadi perubahan pembacaan pada sensor. Kemudian jika tombol button ditekan maka berita akan pindah ke berita selanjutnya dan selesai.

\section{HASIL PENELITIAN DAN PEMBAHASAN}

Perancangan ini merupakan sebuah rancangan mading yang berisi mengenai informasi sekolah seperti pengumuman pengumuman penting yang hendak disampaikan pada siswa, kegiatan-kegiatan lomba untuk siswa, kegiatan sekolah seperti informasi kegiatan ekstrakrikuler, dan lain sebagainya.

Rekaman audio ditampilkan secara simpel dengan pemanfaatan audio sehingga dapat menarik minat siswa siswi SD Muhammadiyah 1 Tejoasri dan juga mengurangi kebosanan pada siswa siswi. Perancangan mading ini diberi sebuah alat sensor gerak pir untuk menangkap sinyal gerak manusia sehinga audio akan berkerja secara otomatis .

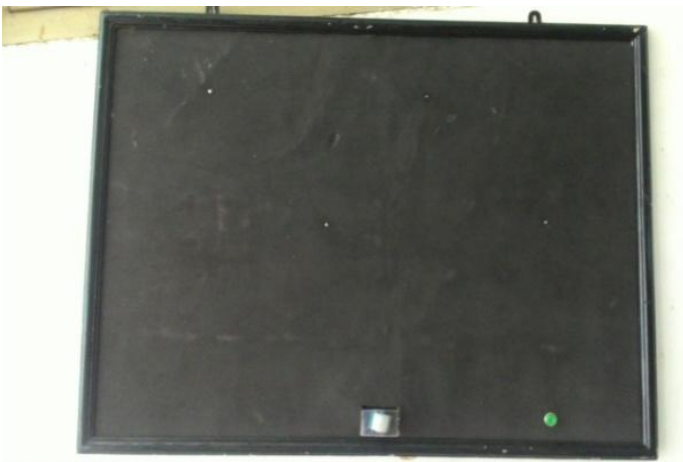

Gambar 5 Perancangan Mading

a) Tombol next

Tombol push button next berguna untuk memindahkan informasi satu, kedua dan selanjutnya. b) Merekam Suara

Suara merupakan salah satu elemen penting dalam perancangan mading ini karena sebagai sumber informasi yang akan disampaikan.

c) Convert suara

Convert suara di lakukan agar rekaman yang sebelumnya direkam di hp menggunakan format AMR menjadi mp3.

Sensor PIR memiliki jangkauan jarak yang bervariasi, tergantung karakteristik sensor. Proses penginderaan sensor PIR dapat digambarkan sebagai berikut:

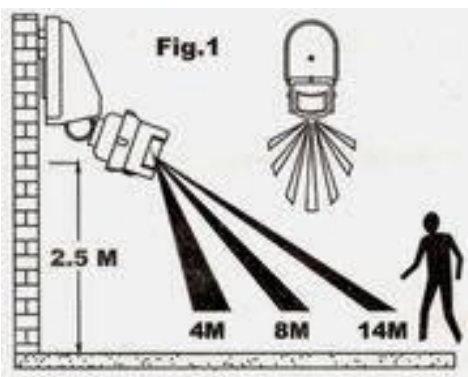

Gambar 6 Cara Kerja Sensor PIR

Pada umumnya sensor PIR memiliki jangkauan pembacaan efektif hingga 5 meter, dan sensor ini sangat efektif digunakan sebagai human detector. Pada pengujian sistem mading bersuara Sensor gerak pir ini di lakukan dalam 3 kali sehingga hasilnya dapat di peroleh sebagai berikut :

1. Jarak $50 \mathrm{~cm}$ alat ini masih dapat mendeteksi objek

2. Jarak $200 \mathrm{~cm}$ masih mendeteksi objek

3. Jarak lebih $600 \mathrm{~cm}$ sistem tidak dapat menjangkau objek .

4. Maksimal jarak sensor yang dapat di jangkau $\pm 500 \mathrm{~cm}$.

Hasil dari pengujian sistem di atas adalah sensor mampu mendeteksi objek yang melewati mading dari jarak $5 \mathrm{~cm}$ sampai $300 \mathrm{~cm}$. 


\section{KESIMPULAN DAN SARAN}

Setelah menyelesaikan rancang bangun mading bersuara menggunakan sensor Gerak (PIR) di SD Muhammadiyah 1 Tejoasri - Kab. Lamongan ini, penulis menarik beberapa kesimpulan sebagai berikut :

1. Mading bersuara menggunakan sensor Gerak (PIR) di SD Muhammadiyah 1 Tejoasri - Kab. Lamongan ini memiliki sensor yang mampu mendeteksi objek yang melewati mading dari jarak $5 \mathrm{~cm}$ sampai 300 $\mathrm{cm}$.

2. Mading bersuara menggunakan sensor Gerak (PIR) di SD Muhammadiyah 1 Tejoasri - Kab. Lamongan ini memberikan informasi tidak hanya melalui tulisan melainkan juga melalui audio, lebih variatif dengan adanya media audio

Beberapa saran untuk pengembangan dan perbaikan pada penelitian ini, antara lain: perlu adanya penambahan rekaman suara untuk isi informasinya bukan hanya tag line saja.

\section{DAFTAR PUSTAKA}

http://sainsdanteknologiku.blogspot.com, Diakses pukul 15:00 Tanggal 09 Juni 2015 http://sainsdanteknologiku.blogspot.com, Diakses pukul 15:00 Tanggal 09 Juni2015 http://itnet-

padang.blogspot.com/2012/12/pengertianmemory-card.html, Diakses pukul 08:50 , Tanggal 22 Mei 2015

http://inbroshare.blogspot.com/2011/10/jeni s-jenis-mikrokontroler.html, Diakses pukul 07:30 Tanggal 13 Juni 2015

http://smadapinrang.blogspot.com/2010/07/pengertiandan-manfaat-mading.html, Diakses pukul 21:00 Tanggal 10 Juni 2015 http://afrianties.blogspot.com/2012/09/perk embangan-mp3.html, Diakses pukul 13:20 Tanggal 22 Mei 2015 
